\title{
Interaction Between Caveolin-1 Polymorphism with Dietary Fat Quality Indices and the Relationship with Visceral Adiposity Index (VAl) and Body Adiposity Index (BAl) Among Overweight and Obese Women: A Cross-Sectional Study
}

\section{Rasool Ghaffarian Ensaf}

Islamic Azad University, Science and Research Branch

\section{Farideh Shiraseb}

Tehran University of Medical Sciences (TUMS)

Atieh Mirzababaei

Tehran University of Medical Sciences (TUMS)

\section{Cain Clark}

Coventry University

Khadijeh Mirzaei ( $\nabla$ mirzaei_kh@tums.ac.ir )

Tehran University of Medical Sciences (TUMS)

\section{Research Article}

Keywords: Caveolin-1 polymorphism, Visceral adiposity index, Body adiposity index, Dietary fat quality indices

Posted Date: December 14th, 2021

DOI: https://doi.org/10.21203/rs.3.rs-1148880/v1

License: (c) (i) This work is licensed under a Creative Commons Attribution 4.0 International License. Read Full License 


\section{Abstract \\ Background \& Aims:}

Caveolin-1(CAV-1) in adipocyte tissue, and other parts of body, possess numerous biological functions. In the present study, we sought to investigate the interaction between CAV-1 polymorphism with dietary fat quality indices and the relationship with visceral adiposity index (VAI) and body adiposity index (BAI) among overweight and obese women.

\section{Methods}

This study was conducted on 386 women, aged 18-48 years old. Biochemical measurements were measured by standard protocols. We used a food frequency questionnaire (FFQ) to calculate the dietary intake and the indices of dietary fat quality intake. Anthropometric values and body composition were measured by standard methods. Finally, the CAV-1 genotype was measured using PCR-RFLP method.

\section{Results}

We found a marginally significant difference in waist-to-hip ratio (WHR) $(P=0.06)$ and $B A I(P=0.06)$ of participants, after adjusting with potential cofounders. For dietary intakes, after adjusting with the energy intake, mean differences in biotin $(P=0.04)$ and total fiber $(P=0.06)$ were significant and marginally significant, respectively. The interaction between two risk allele genotype group (AA) with omega- 6 to omega-3 ratio (W6/W3) on BAl, after adjustment with potential cofounders (age, physical activity, energy intake, education), was marginally positive $(\beta=14.08,95 \% \mathrm{Cl}=-18.65,46.81, \mathrm{P}=0.07)$. In comparison to the reference group (GG), there was a positive interaction between the two risk allele (AA) with W6/W3 ratio on $\operatorname{VAl}(\beta=2.81,95 \% \mathrm{Cl}=1.20,8.84, \mathrm{P}=0.06)$ in the adjusted model.

\section{Conclusions}

We found that there may be an interaction between CAV-1 genotypes with dietary quality fat indices on VAl and BAl among overweight and obese women.

\section{Introduction}

Overweight and obesity represent notable risk factors for many non-communicable diseases, and contributes significantly to global mortality rates $(1-3)$. Indeed, it has been estimated that by 2030 , the prevalence of obese and overweight will increase significantly (4). Obesity and overweight are associated with many diseases and clinical conditions, such as diabetes, cardiovascular disease (CVD), disability, and depression, and early mortality (5). 
Various anthropometric indexes can be used to get an overview of the body composition and health status of the body (6). For example, body mass index (BMI), hip circumference (HC), waist circumference (WC), and WHR can be used to measure and monitor obesity (7). In recent years, novel anthropometric indices have been introduced in an effort to accurately measure body fat distribution, such as VAI and BAI (8). BAl appears to represent a good assessment of fat percentage using HC, height, and gender (9). Whilst VAl is used to evaluate adipose tissue and its function, and, in addition to gender, it uses anthropometric parameters, such as waist circumference and body mass index and also biochemical parameters such as blood triglyceride concentration and blood cholesterol (10).

Throughout the body, including adipose tissue, the plasma membrane contains small $(50-100 \mathrm{~nm})$ complex, invaginations, flask-shaped specialized structures, called caveolae, that contains cholesterol and sphingolipids in its structure (11). Caveolae are involved in lipid metabolism, signal transduction, and endocytosis (12-15), in addition to the metabolism of lipids(16). Caveolae contain proteins called caveolin (17), which are integral membrane proteins that have scaffolding functions, and are regulators of many signaling pathways $(18,19)$. There are three forms of caveolin: caveolin 1 , caveolin 2 , and caveolin 3, which are expressed differently and can all affect obesity (20). Caveolin-1 is predominantly expressed in adipose tissue, caveolin-2 is expressed with caveolin-1 to form hetero-oligomers and, finally, caveolin-3 is the muscle-specific isoform of caveolin $(12,15)$. Caveolin, as an interactive gene, interacts with cholesterol and plays an important role in its metabolism and regulation (21). Due to the notable interaction of caveolin with cholesterol, animal studies have shown the significant effect of a highcholesterol diet on the expression of the caveolin gene (22).

The quality of dietary fat has been reported to be closely related to obesity and body fat percentage, and to examine this relationship, the positive and negative effects of different fats and fatty acids in the diet should be examined (23). Indeed, most studies have been performed on the role of diet in the expression of the caveolin gene in animals. According to such studies, caveolin can be influenced and regulated by obesity and diet (24). Fat consumption is known to impact adipose tissue (25). Moreover, in order to evaluate the quality of dietary fat, several indicators can be used, including cholesterol-saturated fat index (CSI) (26) and W6/W3 ratio (27).

This study sought to investigate the interaction between the quality of dietary fat intake and the CAV-1 gene and their relationship with visceral adiposity index and body adiposity index.

\section{Methods And Materials}

\subsection{Participants}

A total of 386 women, aged 18-48 years old, were randomly selected from among participants in a crosssectional study performed in 2016-2017. The inclusion criteria were: obese or overweight (BMI > 25 $\left.\mathrm{kg} / \mathrm{m}^{2}\right)$, no alcohol consumption, and no smoking. Women with CVD, kidney failure, stroke, thyroid disease, liver disease, cancer, inflammatory illnesses, and those taking any therapeutic medications and 
weight loss supplements, or any supplements that affect weight, were excluded from the study. Pregnant and menopausal women and those who reported a total daily energy intake outside of 800-4200 kcal (3344- $17556 \mathrm{~kJ})$ were also excluded from the study. The study protocol was approved by the ethics committee of Tehran University of Medical Sciences (TUMS) with the following identification:

IR.TUMS.VCR.REC.1397.920. All methods were carried out in accordance with relevant guidelines. All participants of study completed a written informed consent.

\subsection{Measurement of biochemical parameters}

All blood samples were collected at the Nutrition and Biochemistry laboratory of the School of Nutritional Sciences and Dietetics, TUMS. Serum triglycerides (TG) concentrations were assayed with triacylglycerol kits (Pars Azmoon Inc, Tehran, Iran) by using enzymatic colorimetric tests with Glycerol-3-phosphate oxidase Phenol 4-Aminoantipyrine Peroxidase (GPO-PAP). Total cholesterol (total-chol) levels were measured by the cholesterol oxidase Phenol 4-Aminoantipyrine Peroxidase (CHOD-PAP), and low-density lipoprotein (LDL), and high-density lipoprotein (HDL) were measured by the direct method and immune inhibition.

\subsection{Assessment of anthropometric measures}

Weight was measured with digital scales and recorded to the nearest $100 \mathrm{~g}$ while the subjects were minimally clothed and unshod. Height was measured using a tape measure while the subjects were standing, unshod, and had shoulders in a normal position. BMI was calculated by dividing the weight by the square of the height, waist circumference (WC) was measured at the narrowest part of the abdomen, $\mathrm{HC}$ was measured as the maximum circumference over the buttocks, and the minimal circumference was recorded to the nearest $0.1 \mathrm{~cm}$. To reduce error, all measurements were taken by the same technician. For measuring the fat distribution, we used BAI and VAI (for women) with the following formulas:

- BAl was calculated using the following formula (9):

$\mathrm{BAI}=\frac{\text { Hip Circumference }(\mathrm{cm})}{\text { height }(m)^{1.5}}-18$

- VAl was calculated using the formula (10):

Women: VAI $=\left(\frac{\text { Waist Circumference }(\mathrm{cm})}{36.58+(1.89 \times B M I)}\right) \times\left(\frac{T G}{0.81}\right) \times\left(\frac{1.52}{H D L}\right)$ 


\subsection{Assessment of dietary intake}

To evaluate the dietary intake of participants, we used a 147-item semi-quantitative FFQ, with high validity and reliability (28), during face-to-face interviewing. The extracted FFQ values were then changed to grams/day. For the evaluation of macro-and micronutrient content, N4 software was used.

\subsection{Measurement of Fat quality indices}

Fat quality indices include CSI and W6/W3 ratio which are calculated through their respective formulas.

- CSI: Indicates the state of cholesterol and saturated fats, which helps a person in self-care against the state of cholesterol (26).

$\mathrm{CSI}=\frac{\text { Cholesterol }}{\text { Saturated fat }}$

- w-6/w-3 ratio: Omega 6/Omega 3 are two essential fats that are categorized as PUFAs. The total amount of omega-6s and omega-3s are divided by each other to get a ratio (27).

$$
W-6 / W-3 \text { Ratio }=\frac{\sum \omega-6}{\sum \omega-3}
$$

\subsection{Genotyping}

For genotyping the Cav-1 polymorphisms, DNA was extracted from whole blood via a Mini Columns kit (Type G; Genall; Exgene). The polymerase chain reaction-restriction fragment length polymorphism (PCRRFLP) technique was employed to investigate Cav-1 polymorphisms (rs3807992) in gene fragments (major allele $\mathrm{G}$ and minor allele $\mathrm{A}$ ). PCR was carried out using the following primers:

F:3'AGTATTGACCTGATTTGCCATG5'R:5'GTCTTCTGGAAAAAGCACATGA-3', according to pervious study (29). We gave risk allele genotypes $G G, A G$, and $A A$ the values 2,1 , and 0 .

\subsection{Assessment of other variables}

We assessed the physical activity of the participants with a validated International Physical Activity Questionnaire (IPAQ) (30). According to IPAQ scoring protocol, the participants were divided into 3 categories of physical activity: (1) low active (<600 MET- min/week); (2) moderate active ( $\geq 600 \mathrm{MET}$ min/week); and (3) high active ( $\geq 3000 \mathrm{MET}$ - min/week) (31). We also designed and used a standard 
socio-economic demographic questionnaire to collect general background information, including education, and marital status.

\subsection{Statistical Analysis}

Statistical analysis was performed using SPSS v. 25 software (SPSS Inc., IL, USA) and the significance level was, a priori, considered $P \leq 0.05$, while $P=0.06$ was considered as marginally significant. There were no missing values in the analysis. Our data followed a normal distribution, which was confirmed using the Kolmogorov-Smirnov test. All data were expressed as means and standard deviation (SD), and categorical variables were expressed as numbers and percentages. The Pearson's chi-square test was used for categorical variables and to determine the Hardy-Weinberg Equilibrium. One-way analysis of variance (ANOVA) was used to evaluate the association between dietary intake indices, anthropometric parameters, and biochemical parameters, and analysis of covariance (ANCOVA) was used to evaluate and control for confounders. BMI consider as collinear variable for anthropometrics and body composition variables, these variables control with energy intake, age and, physical activity. To investigate the mean differences between groups, post-hoc multiple comparison analysis (Bonferroni corrected), was used. To estimate interactions between CAV-1 genotypes and VAI and BAI, we used a generalized linear model, conducting a crude and adjusted model, where we controlled several potential cofounders (age, energy intake, physical activity, education). The reference group was genotype without risk allele (GG).

\section{Result}

\subsection{Study population characteristics}

A total of 386 overweight and obese women were evaluated in this study. The participant characteristics were: age 36.67 (9.10) years, BMI 31.26 (4.29) kg/m², VAl 2.48 (2.13), BAI 29.58 (7.62), CSI 9.74 (3.43), and W6/W3 ratio $12.65(0.10)$. Among the participants, $286(70.8 \%)$ women were married and 110 (27.2\%) had a good economic status. The overall prevalence of CAV-1 genotypes in the study was $50 \%$ (193), 23.3\% (90), and 25.5\% (103) for AA, AG, and AA respectively.

\subsection{Baseline characteristics of study participants among the CAV-1 genotypes}

The baseline characteristics of study participants, categorized according to the CAV-1 genotypes, are presented in Table 1. As shown in this table, P-values for all variables were reported before the adjustment in the crude model, and after adjustment with potential confounders including age, physical activity, energy intake, and BMI. BMI was considered as collinear for anthropometrics and body composition variables. In the crude model, there was a significant mean difference among the study participants in terms of $B M I(P=0.01)$, diastolic blood pressure (DBP) $(P=0.02), H D L(P=0.001), L D L$ $(P=0.03)$, and $\operatorname{VAl}(P=0.006)$. After adjustment with potential cofounders, the mean difference became marginally significant in the WHR and BAI of participants. The mean difference of HDL and VAl remained 
significant in the adjusted model. According to Bonferroni post-hoc testing, the mean difference in WHR, $\mathrm{VAl}$, and HDL was between AA and GG genotype groups, such that the mean was higher in AG genotype for WHR and VAl, and for HDL was higher in GG genotype; while, in BAl, there was a difference between $A A$ and $A G$ genotypes, such that in the AG genotype was higher. In categorical variables, a significant mean difference among the participants was seen in terms of their education status after controlling for cofounders. There was no significant difference in terms of other variables in Table 1. 
Table1. Baseline characteristics of study participants categorized according to the Cav-1 genotypes in obese and overweight women $(n=386)$

Variables

CAV-1 genotypes

GG ( $N=193) \quad A G(\mathrm{~N}=90)$

Mean \pm SD

$\mathrm{AA}(\mathrm{N}=101)$

$\begin{array}{ll}\mathrm{P}- & \mathrm{P}- \\ \text { value } & \text { value* }\end{array}$

Demographic characteristics

\begin{tabular}{llllll} 
Age $(\mathrm{Y})$ & $37.56 \pm 9.49$ & $35.85 \pm 8.91$ & $35.67 \pm 8.71$ & 0.15 & 0.33 \\
\hline Onset of obesity $(\mathrm{Y})$ & $23.04 \pm 10.02$ & $23.76 \pm 9.04$ & $22.59 \pm 8.41$ & 0.72 & 0.19 \\
\hline $\begin{array}{l}\text { Physical } \\
\text { activity }(\mathrm{MET} / \mathrm{h})\end{array}$ & $1215.46 \pm$ & $1379.12 \pm$ & $1073.74 \pm$ & 0.74 & 0.77 \\
\hline
\end{tabular}

Anthropometric Measurements

\begin{tabular}{llllll} 
Weight $(\mathrm{kg})$ & $79.71 \pm 10.91$ & $81.10 \pm 12.24$ & $83.01 \pm 14.05$ & 0.08 & 0.38 \\
\hline Height $(\mathrm{cm})$ & $161.30 \pm 6.08$ & $161.27 \pm 5.34$ & $160.68 \pm 5.80$ & 0.66 & 0.80 \\
\hline WC $(\mathrm{cm})$ & $96.61 \pm 15.20$ & $95.57 \pm 18.23$ & $100.26 \pm 12.01$ & 0.16 & 0.25 \\
\hline $\mathrm{HC}(\mathrm{cm})$ & $113.59 \pm 9.49$ & $111.44 \pm 6.76$ & $116.10 \pm 11.07$ & 0.09 & 0.07 \\
\hline BMI $\left(\mathrm{kg} / \mathrm{m}^{2}\right)$ & $30.68 \pm 4.02$ & $31.06 \pm 4.06$ & $32.19 \pm 4.75$ & 0.01 & 0.07 \\
\hline WHR & $0.93 \pm 0.05^{\mathrm{b}}$ & $1.94 \pm 9.59^{\mathrm{b}}$ & $0.94 \pm 0.05$ & 0.19 & $\mathbf{0 . 0 6}$ \\
\hline BAl & $29.35 \pm 7.94$ & $28.57 \pm 8.72^{\mathrm{a}}$ & $30.96 \pm 5.80^{\mathrm{a}}$ & 0.18 & $\mathbf{0 . 0 6}$ \\
VAl & $2.13 \pm 1.24^{\mathrm{b}}$ & $3.27 \pm 3.47^{\mathrm{b}}$ & $2.62 \pm 2.05$ & $\mathbf{0 . 0 0 6}$ & $\mathbf{0 . 0 0 6}$
\end{tabular}

Blood pressure

$\begin{array}{llllll}\text { SBP }(\mathrm{mm} \mathrm{Hg}) & 109.60 \pm 15.05 & 113.05 \pm 17.98 & 112.79 \pm 12.04 & 0.19 & 0.78 \\ \text { DBP }(\mathrm{mm} \mathrm{Hg}) & 75.87 \pm 10.77 & 79.45 \pm 11.63 & 79.22 \pm 8.85 & \mathbf{0 . 0 2} & 0.47\end{array}$

\section{Biochemical variables}

\begin{tabular}{|llllll|}
\hline FBS $(\mathrm{mg} / \mathrm{dL})$ & $87.98 \pm 9.62$ & $87 \pm 11.39$ & $86.91 \pm 8.46$ & 0.70 & 0.74 \\
\hline TC $(\mathrm{mg} / \mathrm{dL})$ & $186.76 \pm 33.74$ & $187.58 \pm 44.95$ & $179.21 \pm 30.67$ & 0.29 & 0.27 \\
\hline TG $(\mathrm{mg} / \mathrm{dL})$ & $113.11 \pm 51.20$ & $126.77 \pm 61.42$ & $123.90 \pm 70.50$ & 0.28 & 0.21 \\
\hline HDL $(\mathrm{mg} / \mathrm{dL})$ & $49.07 \pm 11.16^{\mathrm{b}}$ & $42.84 \pm 11.39^{\mathrm{b}}$ & $44.90 \pm 9.17$ & $\mathbf{0 . 0 0 1}$ & 0.03 \\
\hline LDL $(\mathrm{mg} / \mathrm{dL})$ & $98.88 \pm 22.66$ & $89.49 \pm 26.45$ & $92.54 \pm 24.13$ & $\mathbf{0 . 0 3}$ & 0.08 \\
\hline GOT $(\mathrm{U} / \mathrm{L})$ & $18.27 \pm 7.44$ & $17.96 \pm 7.03$ & $17.95 \pm 9.13$ & 0.95 & 0.53
\end{tabular}


Table1. Baseline characteristics of study participants categorized according to the Cav-1 genotypes in obese and overweight women $(n=386)$

\begin{tabular}{|c|c|c|c|c|c|}
\hline GPT (U/L) & $19.04 \pm 13.95$ & $19.35 \pm 11.66$ & $20.71 \pm 15.81$ & 0.71 & 0.61 \\
\hline \multicolumn{4}{|l|}{ Supplements intake } & 0.18 & 0.83 \\
\hline Yes & $87(57.6 \%)$ & $27(17.9 \%)$ & 37 (24.5\%) & & \\
\hline No & $83(47.7 \%)$ & $42(24.1 \%)$ & $49(28.2 \%)$ & & \\
\hline \multicolumn{4}{|l|}{ Marital status } & 0.98 & 0.20 \\
\hline Single & $55(51.4)$ & $24(22.4)$ & $28(26.2)$ & & \\
\hline Married & $137(50.6)$ & $63(23.2)$ & $71(26.2)$ & & \\
\hline \multicolumn{4}{|l|}{ Education status } & 0.17 & 0.009 \\
\hline Illiterate & $1(25)$ & $2(50)$ & $1(25)$ & & \\
\hline Under diploma & $20(41.7)$ & $12(25)$ & 16(33.3) & & \\
\hline Diploma & $68(46.6)$ & $33(22.6)$ & $45(30.8)$ & & \\
\hline $\begin{array}{l}\text { Bachelor and higher } \\
\text { than }\end{array}$ & $103(57.2)$ & $40(22.2)$ & $37(20.6)$ & & \\
\hline \multicolumn{4}{|l|}{ Economic status } & 0.20 & 0.23 \\
\hline Poor & $39(45.3)$ & $19(22.1)$ & $28(32.6)$ & & \\
\hline Moderate & $83(47.4)$ & $46(26.3)$ & $46(26.3)$ & & \\
\hline Good & $62(59)$ & 19(18.1) & $24(22.9)$ & & \\
\hline \multicolumn{4}{|c|}{ Family history of obesity } & 0.55 & 0.15 \\
\hline Yes & $129(51.2)$ & $56(22.2)$ & $67(26.6)$ & & \\
\hline No & $48(45.3)$ & $28(26.4)$ & $30(28.3)$ & & \\
\hline
\end{tabular}


Table1. Baseline characteristics of study participants categorized according to the Cav-1 genotypes in obese and overweight women $(n=386)$

SD: Standard Deviation, IPAQ: International Physical Activity Questionnaire, WC: Waist Circumference, BAl: Body Adiposity Index, VAl: Visceral Adiposity Index, SBP: Systolic Blood Pressure, DBP: Diastolic Blood Pressure, TG: Triglyceride, HDL: High Density Lipoprotein, LDL: Low Density Lipoprotein, GOT: Glutamic Oxaloacetic Transaminase, GPT: Glutamate Pyruvate Transaminase, BMI: Body Mass Index, HC: Hip Circumference, WHR: Waist-to-Hip Ratio, TC: Total cholesterol

Values are represented as means \pm SD. BMI is collinear.

Categorical variables: $\mathrm{N}(\%)$

Independent $\mathrm{T}$ test ( $\mathrm{P}$ value) was performed to identify significant differences between Cav-1 genotypes in crude model

ANCOVA ( $P$ value*) was performed to adjusted potential confounding factors (age, energy intake, Physical activity, BMI)

BMI consider as collinear variable for anthropometrics and body composition variables, these variables control with energy intake, age and, physical activity

p-values $<0.05$ were considered as significant.

a The significant difference was seen between $A A$ and $A G$

b The significant difference was seen between GG and AG

\subsection{Dietary intakes of all subjects according to CAV-1 genotypes in obese and overweight women}

Dietary intakes of all subjects according to CAV-1 genotypes in obese and overweight women are presented in Table 2. Regarding fat components of foods, no significant difference was found in crude and adjusted models. The result was the same for macronutrients and energy, with no significant difference in the crude and adjusted models. According to micronutrients, there was no significant difference among participants in the crude model. But after adjustment for energy intake, mean differences in Biotin $(P=0.04)$ and total fiber $(P=0.06)$ were significant and marginally significant, respectively. There was no significant difference in terms of other variables in Table 2. 
Table2. Dietary food intakes of all subjects according to Cav-1 genotypes in obese and overweight women $(n=386)$

\section{Variables}

\begin{tabular}{|c|c|c|c|c|}
\hline GG $(n=193)$ & AG $(n=90)$ & $\mathrm{AA}(\mathrm{n}=101)$ & \multirow{2}{*}{$\begin{array}{l}\mathrm{P}- \\
\text { value }\end{array}$} & \multirow{2}{*}{$\begin{array}{l}\text { P- } \\
\text { value }^{a}\end{array}$} \\
\hline Mean $\pm S D$ & & & & \\
\hline
\end{tabular}

\section{Fat Components of foods}

\begin{tabular}{|llllll|}
\hline Cholesterol (g/d) & $259.32 \pm 8.95$ & $256.24 \pm 13.73$ & $242.17 \pm 12.18$ & 0.51 & 0.26 \\
\hline $\begin{array}{l}\text { Saturated Fats } \\
\text { (mg/d) }\end{array}$ & $28.55 \pm 0.94$ & $28.19 \pm 1.45$ & $27.12 \pm 1.28$ & 0.66 & 0.23 \\
\hline MUFA (mg/d) & $31.50 \pm 0.95$ & $31.35 \pm 1.46$ & $31.01 \pm 1.30$ & 0.95 & 0.73 \\
\hline PUFA (mg/d) & $19.99 \pm 0.72$ & $20.14 \pm 1.10$ & $20.29 \pm 0.98$ & 0.96 & 0.99 \\
\hline Linoleic acid (mg/d) & $17.28 \pm 0.68$ & $17.38 \pm 1.05$ & $17.53 \pm 0.93$ & 0.97 & 0.99 \\
\hline Linolenic acid (mg/d) & $1.20 \pm 0.05$ & $1.30 \pm 0.08$ & $1.23 \pm 0.07$ & 0.60 & 0.62 \\
\hline EPA (mg/d) & $0.03 \pm 0.003$ & $0.03 \pm 0.005$ & $0.03 \pm 0.00$ & 0.61 & 0.63 \\
\hline DHA (mg/d) & $0.10 \pm 0.01$ & $0.10 \pm 0.01$ & $0.12 \pm 0.01$ & 0.56 & 0.59 \\
\hline Trans fats (mg/d) & 0.001 & 0 & 0.001 & 0.08 & 0.07 \\
\hline CSI & $9.49 \pm 0.26$ & $9.50 \pm 0.40$ & $9.36 \pm 0.35$ & 0.95 & 0.96 \\
\hline W6/W3 & $12.65 \pm 0.009$ & $12.64 \pm 0.01$ & $12.64 \pm 0.01$ & 0.95 & 0.17 \\
\hline Macronutrients and Energy & $2621.64 \pm$ & $2597.22 \pm$ & $2677.85 \pm$ & 0.84 & - \\
\hline Energy(Kcal) & 721.37 & 723.78 & 858.75 & & 0.07 \\
\hline Carbohydrate (gr/day) & $370.78 \pm 10.29$ & $374.19 \pm 15.79$ & $379.33 \pm 14.01$ & 0.88 & 0.84 \\
\hline Protein (g/d) & $88.49 \pm 2.43$ & $90.42 \pm 3.73$ & $88.32 \pm 3.31$ & 0.89 & 0.73 \\
\hline Total fat (gr/day) & $94.10 \pm 2.71$ & $95.89 \pm 4.16$ & $93.89 \pm 3.69$ & 0.92 & 0.77 \\
\hline Micronutrients & & & & 0.44 & 0.07 \\
\hline Sodium (mg/d) & $4200.47 \pm$ & $4406.56 \pm$ & $4237.80 \pm$ & 0.64 & 0.59 \\
\hline Potassium (mg/d) & $4360.21 \pm$ & $4449.45 \pm$ & $4143.65 \pm$ & 0.69 & 0.51 \\
\hline $\begin{array}{l}\text { Vitamin A(RAE) } \\
\text { (mg/d) }\end{array}$ & $801.97 \pm 34.99$ & $753.84 \pm 53.71$ & $764.69 \pm 47.64$ & 0.69 \\
\hline & & & & & \\
\hline
\end{tabular}




\begin{tabular}{|c|c|c|c|c|c|}
\hline Beta carotene $(\mathrm{mg} / \mathrm{d})$ & $\begin{array}{l}5490.89 \pm \\
303.02\end{array}$ & $\begin{array}{l}5219.52 \pm \\
465.11\end{array}$ & $\begin{array}{l}4940.81 \pm \\
412.53\end{array}$ & 0.55 & 0.45 \\
\hline Vitamin C (mg/d) & $197.04 \pm 10.81$ & $194.27 \pm 16.59$ & $197.43 \pm 14.71$ & 0.98 & 0.94 \\
\hline Calcium (mg/d) & $\begin{array}{l}1161.14 \pm \\
35.38\end{array}$ & $\begin{array}{l}1184.05 \pm \\
54.31\end{array}$ & $\begin{array}{l}1156.44 \pm \\
48.17\end{array}$ & 0.92 & 0.83 \\
\hline Iron (mcg/d) & $18.65 \pm 0.50$ & $18.46 \pm 0.77$ & $19.02 \pm 0.68$ & 0.85 & 0.51 \\
\hline Vitamin D (ug/d) & $2.01 \pm 0.13$ & $2.05 \pm 0.21$ & $1.92 \pm 0.19$ & 0.88 & 0.83 \\
\hline Vitamin $E(m g / d)$ & $17.61 \pm 0.77$ & $16.84 \pm 1.19$ & $17.63 \pm 1.05$ & 0.84 & 0.78 \\
\hline Thiamin $(\mathrm{mg} / \mathrm{d})$ & $2.04 \pm 0.05$ & $2.08 \pm 0.08$ & $2.17 \pm 0.07$ & 0.37 & 0.12 \\
\hline Riboflavin (mg/d) & $2.20 \pm 0.06$ & $2.21 \pm 0.10$ & $2.21 \pm 0.09$ & 0.99 & 0.95 \\
\hline Niacin $(\mathrm{mg} / \mathrm{d})$ & $25.21 \pm 0.78$ & $25.24 \pm 1.20$ & $25.77 \pm 1.06$ & 0.90 & 0.89 \\
\hline Vitamin B6 (mg/d) & $2.18 \pm 1.06$ & $2.22 \pm 0.09$ & $2.10 \pm 0.08$ & 0.60 & 0.16 \\
\hline Total Folate $(\mu \mathrm{g} / \mathrm{d})$ & $\begin{array}{l}603.19 \pm \\
15.003\end{array}$ & $608.42 \pm 23.02$ & $621.79 \pm 20.42$ & 0.76 & 0.73 \\
\hline Vitamin B12 (mcg/d) & $4.26 \pm 0.20$ & $4.37 \pm 0.31$ & $4.54 \pm 028$ & 0.72 & 0.78 \\
\hline Biotin (mcg/d) & $39.70 \pm 1.43$ & $39.03 \pm 2.20$ & $35.26 \pm 1.95$ & 0.17 & 0.04 \\
\hline $\begin{array}{l}\text { Pantothenic acid } \\
\text { (mg/d) }\end{array}$ & $6.56 \pm 0.20$ & $6.63 \pm 0.31$ & $6.28 \pm 0.27$ & 0.63 & 0.27 \\
\hline Vitamin K (mcg/d) & $228.18 \pm 16.61$ & $201.62 \pm 25.49$ & $196.37 \pm 22.61$ & 0.45 & 0.41 \\
\hline Phosphor (mg/d) & $\begin{array}{l}1644.12 \pm \\
43.89\end{array}$ & $\begin{array}{l}1667.96 \pm \\
67.37\end{array}$ & $\begin{array}{l}1606.34 \pm \\
59.76\end{array}$ & 0.78 & 0.30 \\
\hline Magnesium (mg/d) & $464.57 \pm 12.53$ & $463.81 \pm 19.23$ & $445.40 \pm 17.05$ & 0.64 & 0.10 \\
\hline Zinc (mg/d) & $12.94 \pm 0.35$ & $13.13 \pm 0.54$ & $12.75 \pm 0.48$ & 0.87 & 0.45 \\
\hline Copper (mcg/d) & $2.01 \pm 0.06$ & $1.95 \pm 0.09$ & $2.03 \pm 0.08$ & 0.83 & 0.48 \\
\hline Manganese $(\mathrm{mg} / \mathrm{d})$ & $7.02 \pm 0.24$ & $7.40 \pm 0.36$ & $6.92 \pm 0.32$ & 0.58 & 0.46 \\
\hline Selenium $(\mathrm{mcg} / \mathrm{d})$ & $119.26 \pm 3.61$ & $121.68 \pm 5.55$ & $120.58 \pm 4.92$ & 0.93 & 0.96 \\
\hline Chromium (mg/d) & $0.11 \pm 0.007$ & $0.11 \pm 0.01$ & $0.10 \pm 0.01$ & 0.77 & 0.69 \\
\hline Total fiber (g/d) & $44.55 \pm 1.59$ & $43.17 \pm 2.44$ & $48.95 \pm 2.17$ & 0.15 & 0.06 \\
\hline Caffeine $(\mathrm{mg} / \mathrm{d})$ & $145.83 \pm 13.10$ & $177.69 \pm 20.12$ & $141.93 \pm 17.84$ & 0.33 & 0.34 \\
\hline
\end{tabular}


Table2. Dietary food intakes of all subjects according to Cav-1 genotypes in obese and overweight women $(n=386)$

SD: Standard Deviation, MUFA: Monounsaturated Fatty Acid, PUFA: Polyunsaturated Fatty acid, EPA: Eicosapentaenoic Acid, DHA: Docosahexaenoic Acid, CSI: Cholesterol-Saturated Fat Index.

Values are represented as means \pm SD.

Independent $\mathrm{T}$ test ( $\mathrm{P}$ value) was performed to identify significant differences between Cav-1 genotypes in crude model

ANCOVA ( $P$ value*) was performed to adjusted potential confounding factors (energy intake)

p-values $<0.05$ were considered as significant

\subsection{The association of genotype variant of CAV-1 with BAI and VAl in crude and adjusted Linear Regression Models in overweight and obese women}

The association of genotype variant of CAV- 1 with BAI and VAI in the crude and adjusted linear regression model are presented in Table 3. After controlling for the potential cofounders (age, energy intake, physical activity), in comparison to reference group (GG), there was a marginally significant positive association between the AA genotype and $\mathrm{BAI}(\beta=0.94,95 \% \mathrm{Cl}=0.006,4.33, \mathrm{P}=0.06)$. A positive association between AG genotype and VAl, in comparison to reference group (GG), was observed in the crude model $(\beta=67.77$, $95 \% \mathrm{Cl}=26.06,109.48, \mathrm{P}=0.001$ ). On the other hand, after adjusting for cofounders (age, energy intake, physical activity), a positive association was found in comparison to reference group (GG) for the $A A$ and $A G$ genotypes with $\operatorname{VAl}(\beta=42.12,95 \% \mathrm{Cl}=-2.74,86.98, P=0.06),(\beta=84.12,95 \% \mathrm{Cl}=32.16,136.07, P=$ 0.002), respectively. 
Table3. association of genotype variant of Cav-1 with BAl and VAl in crude and adjusted Linear Regression Models in overweight and obese women $(n=386)$

\begin{tabular}{|llllll|}
\hline Variables & Model & Genotypes & B & $95 \%$ Cl & P-value \\
\hline BAI & Crude & AA & 1.60 & $-0.61,3.81$ & 0.15 \\
\cline { 3 - 6 } & & AG & -0.78 & $-3.04,1.47$ & 0.49 \\
\cline { 3 - 6 } & Adjusted & AA & 0.94 & $0.006,4.33$ & $\mathbf{0 . 0 6}$ \\
\cline { 3 - 6 } & Crude & AG & -2.06 & $-5.89,1.76$ & 0.29 \\
\hline & AA & 32.19 & $-5.77,70.16$ & 0.09 \\
\cline { 3 - 6 } & Adjusted & AG & 67.77 & $26.06,109.48$ & $\mathbf{0 . 0 0 1}$ \\
& & AA & 42.12 & $-2.74,86.98$ & $\mathbf{0 . 0 6}$ \\
\cline { 3 - 5 } & & AG & 84.12 & $32.16,136.07$ & $\mathbf{0 . 0 0 2}$ \\
\hline
\end{tabular}

Cl: Confidence Interval, BAI: Body Adiposity Index, VAI: Visceral Adiposity Index

Comparisons between groups were determined based on logistic regression analysis

Generalized linear model Adjusted (age, energy intake, Physical activity, education)

GG consider as reference group

\subsection{Interactions between CAV-1 genotypes and CSI on BAI and VAl in overweight and obese women}

The interaction of CAV-1 genotypes with CSI on BAI and VAI in the crude and adjusted model are presented in Table 4. In the crude model, in terms of BAI, there was a negative interaction between two risk allele risk (AG) with $\mathrm{CSI}(\beta=-0.30,95 \% \mathrm{Cl}=-0.99,0.37, \mathrm{P}=0.38)$ in comparison to the reference group (GG), and after controlling for potential cofounders (age, physical activity, energy intake, education), this interaction remained negative between $A G$ and $C S I(\beta=-0.58,95 \% \mathrm{Cl}=-1.67,0.50, P=0.29)$. For VAl, a positive interaction was observed between two risk allele (AA) with CSI in the crude and adjusted model, in comparison to reference group (GG) $(\beta=0.11,95 \% \mathrm{Cl}=-0.09,0.31, P=0.28),(\beta=0.11,95 \% \mathrm{Cl}=0.11,0.34$, $P=0.04$ ), respectively (Figure 1$)$. 
Table 4. Interactions between Cav-1 genotypes and dietary fat quality indices in overweight and obese women $(n=386)$

Interaction type

BAI

Crude

$A A^{*} \mathrm{CSI}$

$A G * C S I$

Adjusted

$A A^{*} C S I$

$A G^{*} \mathrm{CSI}$

BAI

Crude

$A A * W 6 / W 3$

$A G * W 6 / W 3$

Adjusted

$A A * W 6 / W 3$

$A G * W 6 / W 3$

VAI

\section{Crude}

$A A^{*} \mathrm{CSI}$

$\mathrm{AG}^{\star} \mathrm{CSI}$

Adjusted

$A A^{*} \mathrm{CSI}$

$\mathrm{AG}^{*} \mathrm{CSI}$

VAI

Crude

$A A^{*} W 6 / W 3$

$A G * W 6 / W 3$

Adjusted
$-0.16$

$-0.64,0.61$

0.96

$-0.30$

$-0.99,0.37$

0.38

$\begin{array}{lll}4.03 & -22.02,30.09 & 0.76 \\ -6.45 & -37.63,24.73 & \mathbf{0 . 6 8}\end{array}$

14.08

$18.65,46.81$

0.07

$-12.91$

$-52.43,26.61$

0.52

0.49

0.29

P-value
$-1.41,0.68$

$-1.67,0.50$ 
Table 4. Interactions between Cav-1 genotypes and dietary fat quality indices in overweight and obese women $(n=386)$

\begin{tabular}{|c|c|c|c|}
\hline$A A^{*} W 6 / W 3$ & 2.81 & $1.20,8.84$ & 0.06 \\
\hline$A G^{*} W 6 / W 3$ & -5.66 & $-14.79,3.46$ & 0.22 \\
\hline
\end{tabular}

Cl: Confidence Interval, BAI: Body Adiposity Index, VAl: Visceral Adiposity Index, CSI: CholesterolSaturated fat Index

$P$ value with unadjusted (crude)

P value with adjustments for potential confounding factors including (Age, Physical activity, energy intake, education)

\subsubsection{Interactions between CAV-1 genotypes and W6/W3 ratio on BAI and VAl in overweight and obese women}

In the crude model, the interaction between one risk allele group (AG) with W6/W3 ratio on BAl, in comparison to reference group (GG), was negative, but not significant $(\beta=-6.45,95 \% \mathrm{Cl}=-37.63,24.73, P=$ 0.68 ), and the interaction between two risk allele genotype group (AA) with W6/W3 ratio on BAI after adjustment with potential cofounders (age, physical activity, energy intake, education) was marginally positive $(\beta=14.08,95 \% \mathrm{Cl}=-18.65,46.81, \mathrm{P}=0.07)$ (Figure 2$)$. In terms of $\mathrm{VAl}$, in comparison to reference group (GG), there was a positive interaction between two risk allele (AA) with W6/W3 ratio $(\beta=2.81$, $95 \% \mathrm{Cl}=1.20,8.84, \mathrm{P}=0.06$ ) in the adjusted model (Figure 3 ).

\section{Discussion}

To our knowledge, this cross-sectional study is the first study to have investigated the interaction between CAV-1 genotypes and dietary fat quality indices on VAI and BAI among overweight and obese women. Accordingly, our results showed that there may be an interaction between CAV-1 genotypes and dietary fat quality indices (CSI, W6/W3 ratio) on BAI and VAl in overweight and obese women.

We found that the interaction of increased adherence to W6/W3 ratio consumption with AA carriers of CAV-1 was positive on VAl and BAI, additionally, we noted a positive interaction between CSI with AA risk allele on VAl. To our knowledge, no study has been conducted directly on this subject, but according to some related studies, CAV-1 may have a direct impact on the regulation of HDL, TG, and cholesterol, and in general, CAV- 1 impacts on fatty acid metabolism $(21,32,33)$. In another study, the CAV-1 expression was decreased in adipocytes of obese subjects (34). An animal study showed that consumption of a high-cholesterol diet can affect the expression of CAV-1 (22). We found that the AA risk allele group of CAV-1 has higher BAl than other groups, whilst in terms of VAl, the AG genotype group was higher than others. BAI and VAI represent novel indicators of obesity that have been scarcely studied $(35,36)$. Female AA allele risk had a significantly higher BMI compared to the reference group (GG), which is consistent 
with previous studies (29). According to Catalan et al, CAV-1 expression in visceral adipose tissue and subcutaneous adipose tissue is associated positively BMI and body fat (32).

According to our results, females with the AG risk allele have higher WHR and DBP values in comparison to the GG group, whilst the value of HDL and LDL was higher in the reference group (GG). As previously mentioned, CAV-1 has a critical role in lipid homeostasis, which can affect adipose tissue, blood vessels, and liver, to alter the regulation of TG, cholesterol, VLDL, and HDL (33). However, our results did not show any significant difference in macronutrients, energy, and fat components of foods of subjects, with the only difference found in biotin and total fiber.

Caveolae are formed from lipid rafts and contain cholesterol, glycosphingolipids, and CAV-1 (37), and can elicit an uptake of lipid metabolites, including several fatty acid species, triacylglycerol, and cholesterol, $(38-40)$. The roles of CAV-1 are variegated, with its' most important functions in cholesterol homeostasis, signal transduction, cellular and systemic lipid metabolism, and regulation of lipid and lipoprotein metabolism $(32,33,41)$. CAV-1 expressed in different parts of the body, such as fibroblasts, epithelial, and endothelial cells, and also in adipocytes (42). It is interesting that the CAV-1 works as an element in lipid droplets and can effect lipid droplet accumulation and breakdown (43). According to Chang et al, a highfat diet causes CAV- 1 to be secreted more in adipose tissue in comparison to a normal diet in mice, therefore, adipose tissue may be considered the main source of CAV-1 secretion (44). Razani et al found that CAV-1 in adipocyte and endothelial cells has an effect on obesity, mediated by diet (45). Moreover, some studies have shown that CAV- 1 acts as a tumor suppressing protein by inhibiting the functional signaling activity of several mutated genes, and thus disrupts the cell transformation process (46-54). The mechanism by which CAV- 1 acts as a tumor suppressor remains under investigation, however, may putatively be because CAV-1 is a scaffolding protein and interacts with and regulates signaling pathways, in addition to a possibility that this protein may regulate proto-oncogenes (12). Moreover, cytokines like TNF-A and IL-1B can effect CAV-1 mRNA expression (55).

CAV-1 is involved in lipogenesis and adipogenic processes as CAV-1 mRNA (56)., and CAV-1 can functionally suppress transforming growth factor-beta (TGF- $\beta$ ) by modifying the phosphorylation state of SMAD., Another potential mechanism is that the interaction between CAV-1 with transforming growth factor-beta type 1 receptor (TaR-1) may influence TGF- $\beta$ inhibition (55). Further, CAV- 1 can impact cytokine signaling by interactions with the janus kinase (JAK) family, cytokine receptors, and the proteasome pathway $(15,57)$.

There are several limitations in the present study that must considered when interpreting out findings. This study was a cross-sectional study, thereby precluding causal inferences being drawn. Next, the sample size used to conduct this study was small, and we used a FFQ to investigate the intakes of subjects, which, given its' self-reported nature, may be influenced by recall bias. Furthermore, this study was conducted only on women, so that results may not generalized to all sexes. Nevertheless, despite the noted limitations, our study has numerous strengths, including; this is, to our knowledge, the first study to have investigated the interaction between CAV-1 genotypes with dietary fat quality indices on VAI and BAI 
among overweight and obese women, moreover, we used detailed genetic factors in the study. Further, since we conducted this study on women only, greater specificity and insight maybe gleaned.

\section{Conclusion}

Based on the findings of the present study, it appears that there may be an interaction between CAV-1 genotypes with dietary quality fat indices and an association with VAI and BAI among overweight and obese women. Two risk allele (AA) significantly interacted with CSI and W6/W3 ratio consumption, and impacted on BAI and VAI. Nevertheless, we recommend that more studies be done in this area to confirm the veracity of our findings.

\section{Abbreviations}

BAl: body adiposity index; BMI: body mass index; CAV-1: caveolin-1; Cl: confidence interval; CSI: Cholesterol-saturated fat index; CVDs: cardiovascular diseases; DBP: diastolic blood pressure; DNA: deoxyribonucleic acid; FFQ: food frequency questionnaire; HC: hip circumference; HDL: high-density lipoprotein; II-1ß: Interleukin 1 beta; IPAQ: international physical activity questionnaire; JAK: janus kinase; LDL: low-density lipoprotein; MET: metabolic equivalent of task; mRNA: messenger ribonucleic; PUFA: polyunsaturated fatty acid; SD: standard deviation; TG: triglyceride; TGF- $\beta$ : transforming growth factor beta; TNF-a: tumor necrosis factor alpha; T $\beta R$-1: transforming growth factorbeta type 1 receptor; VAl: visceral adiposity index; WC: waist circumference; WHR: waist-to-hip ratio; W6/W3: omega-6 to omega-3 ratio.

\section{Declarations}

\section{Authors' Contributions}

The project was designed and wrote by RGE and KhM. Data were analyzed by FS. Data were collected by $\mathrm{AM}$, and $\mathrm{CC}$ proofread the manuscript for native English writing. All authors read and approved the final manuscript.

\section{Acknowledgements}

The authors thank the study participants for their assistance in physical examinations. They also thank those involved in nutritional assessment and database management. This manuscript has been granted by Tehran University of Medical Sciences (Grant No: 97-03-161-41017).

\section{Competing interests}

The authors express that they have no competing interests.

\section{Availability of data and materials}


The data that confirm the findings of this study are available from Khadijeh Mirzaei Data are available from the authors upon reasonable request and with permission of Khadijeh Mirzaei.

\section{Consent for publication}

Informed written consent for the publication of information or other personal information was obtained from all study participants.

\section{Ethics approval and consent to participate}

Ethics approval for the study protocol was confirmed by The Human Ethics Committee of Tehran University of Medical Sciences (TUMS) with the following identification:

IR.TUMS.VCR.REC.1397.920. All participants signed a written informed consent that was approved by the Ethics committee.

\section{Funding}

This manuscript has been granted by Tehran University of Medical Sciences (Grant No: 97-03-16141017). The funder had no role in the design, analysis or writing of this article.

\section{References}

1. Finucane MM, Stevens GA, Cowan M, Lin JK, Paciorek CJ, Singh GM, et al. HHS Public Access participants. Lancet. 2011;377(9765):557-67.

2. Ng M, Fleming T, Robinson M, Thomson B, Graetz N, Margono C, et al. Global, regional, and national prevalence of overweight and obesity in children and adults during 1980-2013: a systematic analysis for the Global Burden of Disease Study 2013. Lancet [Internet]. 2014 Aug;384(9945):76681. Available from: https://linkinghub.elsevier.com/retrieve/pii/S0140673614604608

3. Kelishadi R. Childhood overweight, obesity, and the metabolic syndrome in developing countries. Epidemiol Rev. 2007;29(1):62-76.

4. Kelly T, Yang W, Chen CS, Reynolds K, He J. Global burden of obesity in 2005 and projections to 2030. Int J Obes. 2008;32(9):1431-7.

5. Hruby A, Hu FB. The Epidemiology of Obesity: A Big Picture. Pharmacoeconomics. 2015;33(7):67389.

6. Al-Daghri NM, Al-Attas OS, Wani K, Alnaami AM, Sabico S, Al-Ajlan A, et al. Sensitivity of various adiposity indices in identifying cardiometabolic diseases in Arab adults. Cardiovasc Diabetol. 2015;14(1):1-8.

7. Yong L, GuangHui T, WeiWei T, LiPing L, XiaoSong Q. Can body mass index, waist circumference, waist-hip ratio and waist-height ratio predict the presence of multiple metabolic risk factors in Chinese subjects? BMC Public Health [Internet]. 2011;11(35):(13 January 2011)-(13 January 2011). 
Available from: http://proxy.lib.umich.edu/login?url=http://search.ebscohost.com/login.aspx? direct=true $\& \mathrm{db}=\mathrm{Ihh} \& \mathrm{AN}=20113028577 \&$ site $=$ ehost live\&scope=site\%0Ahttp://www.biomedcentral.com/content/pdf/1471-2458-11-35.pdf\%0Aemail: Liuy@sj-hospital.org\%5Cghtong@126.com\%5Ctongww

8. Saqlain M, Akhtar Z, Karamat R, Iqbal M, Fiaz M, Zafar MM, et al. Body Mass Index versus Other Adiposity Traits: Best Predictor of Cardiometabolic Risk. 2019;48(12):2224-31.

9. Bergman RN, Stefanovski D, Buchanan TA, Sumner AE, Reynolds JC, Sebring NG, et al. NIH Public Access. 2012;19(5):1083-9.

10. Amato MC, Giordano C, Galia M, Criscimanna A, Vitabile S, Midiri M, et al. Visceral Adiposity Index: A reliable indicator of visceral fat function associated with cardiometabolic risk. Diabetes Care [Internet]. 2010 Apr 1;33(4):920-2. Available from: http://care.diabetesjournals.org/cgi/doi/10.2337/dc09-1825

11. Bastiani M, Parton RG. Caveolae at a glance. J Cell Sci. 2010;123(22):3831-6.

12. Cohen AW, Hnasko R, Schubert W, Lisanti MP. Role of caveolae and caveolins in health and disease. Physiol Rev. 2004;84(4):1341-79.

13. Frühbeck G. The Sir David Cuthbertson Medal Lecture Hunting for new pieces to the complex puzzle of obesity. Proc Nutr Soc. 2006;65(04):329-47.

14. Parton RG, Simons K. The multiple faces of caveolae. Nat Rev Mol Cell Biol. 2007;8(3):185-94.

15. Frühbeck $G$, López $M$, Diéguez $C$. Role of caveolins in body weight and insulin resistance regulation. Trends Endocrinol Metab [Internet]. 2007 Jul;18(5):177-82. Available from: https://linkinghub.elsevier.com/retrieve/pii/S1043276007000513

16. Otis JP, Shen MC, Quinlivan V, Anderson JI, Farber SA. Intestinal epithelial cell caveolin 1 regulates fatty acid and lipoprotein cholesterol plasma levels. DMM Dis Model Mech. 2017;10(3):283-95.

17. Song KS, Tang Z, Li S, Lisanti MP. Mutational analysis of the properties of caveolin-1. A novel role for the C-terminal domain in mediating homo-typic caveolin-caveolin interactions. J Biol Chem [Internet]. 1997;272(7):4398-403. Available from: http://dx.doi.org/10.1074/jbc.272.7.4398

18. Inokuchi J. Insulin Resistance as a Membrane Microdomain Disorder. Biol Pharm Bull [Internet]. 2006;29(8):1532-7. Available from: http://www.jstage.jst.go.jp/article/bpb/29/8/29_8_1532/_article

19. Parton RG, Hanzal-Bayer M, Hancock JF. Biogenesis of caveolae: A structural model for caveolininduced domain formation. J Cell Sci. 2006;119(5):787-96.

20. Williams TM, Lisanti MP. The Caveolin genes: From cell biology to medicine. Ann Med. 2004;36(8):584-95.

21. Frank PG, Cheung MWC, Pavlides S, Llaverias G, Park DS, Lisanti MP. Caveolin-1 and regulation of cellular cholesterol homeostasis. Am J Physiol - Hear Circ Physiol. 2006;291(2).

22. Hahn-Obercyger M, Graeve L, Madar Z. A high-cholesterol diet increases the association between caveolae and insulin receptors in rat liver. J Lipid Res [Internet]. 2009;50(1):98-107. Available from: http://dx.doi.org/10.1194/jlr.M800441-JLR200 
23. Barbieiri P, Nunes JC, Torres AG, Nishimura RY, Zuccolotto DCC, Crivellenti LC, et al. Indices of dietary fat quality during midpregnancy is associated with gestational diabetes. Nutrition. 2016;32(6):65661.

24. Lopez IP, Milagro FI, Marti A, Moreno-Aliaga MJ, Martinez JA, De Miguel C. High-fat feeding period affects gene expression in rat white adipose tissue. Mol Cell Biochem. 2005;275(1-2):109-15.

25. Gómez-Ruiz A, Milagro Fl, Campión J, Martínez JA, De Miguel C. Caveolin expression and activation in retroperitoneal and subcutaneous adipocytes: Influence of a high-fat diet. J Cell Physiol. 2010;225(1):206-13.

26. MITCHELL DT, KORSLUND MK, BREWER BK, NOVASCONE MA. Development and Validation of the Cholesterol-Saturated Fat Index (CSI) Scorecard. J Am Diet Assoc [Internet]. 1996 Feb;96(2):132-6. Available from: https://linkinghub.elsevier.com/retrieve/pii/S0002822396000417

27. Simopoulos AP. The importance of the ratio of omega-6/omega-3 essential fatty acids. Biomed Pharmacother. 2002;56(8):365-79.

28. Mirmiran P, Hosseini Esfahani F, Mehrabi Y, Hedayati M, Azizi F. Reliability and relative validity of an FFQ for nutrients in the Tehran Lipid and Glucose Study. Public Health Nutr. 2010;13(5):654-62.

29. Abaj F. Caveolin-1 Genetic Polymorphisms Interact with Fatty Acid Types to Modulate Metabolic Syndrome. :1-17.

30. Aadahl M, Jørgensen T. Validation of a new self-report instrument for measuring physical activity. Med Sci Sports Exerc. 2003;35(7):1196-202.

31. Committee IR. Guidelines for data processing and analysis of the International Physical Activity Questionnaire (IPAQ)-short and long forms. http//www ipaq ki se/scoring pdf. 2005;

32. Catalán V, Gómez-Ambrosi J, Rodríguez A, Silva C, Rotellar F, Gil MJ, et al. Expression of caveolin-1 in human adipose tissue is upregulated in obesity and obesity-associated type 2 diabetes mellitus and related to inflammation. Clin Endocrinol (Oxf). 2008;68(2):213-9.

33. Frank PG, Pavlides S, Cheung MWC, Daumer K, Lisanti MP. Role of caveolin-1 in the regulation of lipoprotein metabolism. Am J Physiol - Cell Physiol. 2008;295(1):242-9.

34. Fernández-Real JM, Catalán V, Moreno-Navarrete JM, Gómez-Ambrosi J, Ortega FJ, RodriguezHermosa $\mathrm{Jl}$, et al. Study of caveolin-1 gene expression in whole adipose tissue and its subfractions and during differentiation of human adipocytes. Nutr Metab. 2010;7:1-9.

35. Blus E, Wojciechowska-Kulik A, Majewska E, Baj Z. Usefulness of New Indicators of Obesity (BAI and VAI) in Estimation of Weight Reduction. J Am Coll Nutr. 2020;39(2):171-7.

36. Jabłonowska-Lietz B, Wrzosek M, Włodarczyk M, Nowicka G. New indexes of body fat distribution, visceral adiposity index, body adiposity index, waist-to-height ratio, and metabolic disturbances in the obese. Kardiol Pol. 2017;75(11):1185-91.

37. Garg A, Agarwal AK. Caveolin-1: A new locus for human lipodystrophy. J Clin Endocrinol Metab. 2008;93(4):1183-5. 
38. Su X, Abumrad NA. Cellular fatty acid uptake: a pathway under construction. Trends Endocrinol Metab [Internet]. 2009 Mar;20(2):72-7. Available from:

https://linkinghub.elsevier.com/retrieve/pii/S1043276009000034

39. Pilch PF, Liu L. Fat caves: Caveolae, lipid trafficking and lipid metabolism in adipocytes. Trends Endocrinol Metab. 2011;22(8):318-24.

40. Grayson TH, Chadha PS, Bertrand PP, Chen H, Morris MJ, Senadheera S, et al. Increased caveolae density and caveolin-1 expression accompany impaired NO-mediated vasorelaxation in diet-induced obesity. Histochem Cell Biol. 2013;139(2):309-21.

41. Otis JP, Shen M-C, Quinlivan V, Anderson JL, Farber SA. Intestinal epithelial cell caveolin 1 regulates fatty acid and lipoprotein cholesterol plasma levels. Dis Model Mech [Internet]. 2017 Mar 1;10(3):283-95. Available from:

https://journals.biologists.com/dmm/article/10/3/283/2244/Intestinal-epithelial-cell-caveolin-1regulates

42. Gámez-Ruiz A, Milagro Fl, Campián J, Martínez JA, De Miguel C. High-fat diet feeding alters metabolic response to fasting/non fasting conditions. Effect on caveolin expression and insulin signalling. Lipids Health Dis. 2011;10:1-10.

43. Cohen AW, Razani B, Schubert W, Williams TM, Wang XB, lyengar P, et al. Role of Caveolin-1 in the Modulation of Lipolysis and Lipid Droplet Formation. Diabetes [Internet]. 2004 May 1;53(5):1261-70. Available from: http://diabetes.diabetesjournals.org/cgi/doi/10.2337/diabetes.53.5.1261

44. Chang C-C, Chen C-Y, Wen H-C, Huang C-Y, Hung M-S, Lu H-C, et al. Caveolin-1 Secreted from Adipose Tissues and Adipocytes Functions as an Adipogenesis Enhancer. Obesity [Internet]. 2017 Nov;25(11):1932-40. Available from: http://doi.wiley.com/10.1002/oby.21970

45. Razani B, Combs TP, Wang XB, Frank PG, Park DS, Russell RG, et al. Caveolin-1-deficient mice are lean, resistant to diet-induced obesity, and show hypertriglyceridemia with adipocyte abnormalities. J Biol Chem [Internet]. 2002;277(10):8635-47. Available from:

http://dx.doi.org/10.1074/jbc.M110970200

46. Sager R. Sheng S, Anisowicz A, Sotiropoulou G, Zou Z, Stenman G, Swisshelm K, Chen Z, Hendrix MJC, Pemberton P, Rafidi K, and Ryan K. In: RNA genetics of breast cancer: maspin as a paradigm Cold Spring Harbor Symp Quant Biol. 1994. p. 537-46.

47. Lee SW, Reimer CL, Oh P, Campbell DB, Schnitzer JE. Tumor cell growth inhibition by caveolin reexpression in human breast cancer cells. Oncogene. 1998;16(11):1391-7.

48. Koleske AJ, Baltimore D, Lisanti MP. Reduction of caveolin and caveolae in oncogenically transformed cells. Proc Natl Acad Sci U S A. 1995;92(5):1381-5.

49. Galbiati F, Volonté D, Engelman JA, Watanabe G, Burk R, Pestell RG, et al. Targeted downregulation of caveolin-1 is sufficient to drive cell transformation and hyperactivate the p42/44 MAP kinase cascade. EMBO J. 1998;17(22):6633-48.

50. Furuchi T, Anderson RGW. Cholesterol depletion of caveolae causes hyperactivation of extracellular signal-related kinase (ERK). J Biol Chem. 1998;273(33):21099-104. 
51. Engelman JA, Zhang XL, Lisanti MP. Sequence and detailed organization of the human caveolin-1 and -2 genes located near the D7S522 locus (7q31.1). Methylation of a CpG island in the 5' promoter region of the caveolin-1 gene in human breast cancer cell lines. FEBS Lett. 1999;448(2-3):221-30.

52. Engelman JA, Zhang XL, Lisanti MP. Genes encoding human caveolin- 1 and -2 are co-localized to the D7S522 locus (7q31.1), a known fragile site (FRA7G) that is frequently deleted in human cancers. FEBS Lett. 1998;436(3):403-10.

53. Engelman JA, Zhang XL, Galbiati F, Lisanti MP. Chromosomal localization, genomic organization, and developmental expression of the murine caveolin gene family (Cav-1, -2, and -3) Cav-1 and Cav-2 genes map to a known tumor suppressor locus (6-A2/7q31). FEBS Lett. 1998;429(3):330-6.

54. Engelman JA, Wykoff CC, Yasuhara S, Song KS, Okamoto T, Lisanti MP. Recombinant expression of caveolin-1 in oncogenically transformed cells abrogates anchorage-independent growth. J Biol Chem [Internet]. 1997;272(26):16374-81. Available from: http://dx.doi.org/10.1074/jbc.272.26.16374

55. Razani B, Zhang XL, Bitzer M, Von Gersdorff G, Böttinger EP, Lisanti MP. Caveolin-1 Regulates Transforming Growth Factor (TGF)- $\beta$ /SMAD Signaling through an Interaction with the TGF- $\beta$ Type I Receptor. J Biol Chem. 2001;276(9):6727-38.

56. Scherer PE, Lisanti MP, Baldini G, Sargiacomo M, Mastick CC, Lodish HF. Induction of caveolin during adipogenesis and association of GLUT4 with caveolin-rich vesicles. J Cell Biol. 1994;127(5):123343.

57. Felley-Bosco E, Bender FC, Courjault-Gautier F, Bron C, Quest AFG. Caveolin-1 down-regulates inducible nitric oxide synthase via the proteasome pathway in human colon carcinoma cells. Proc Natl Acad Sci U S A. 2000;97(26):14334-9.

\section{Figures}




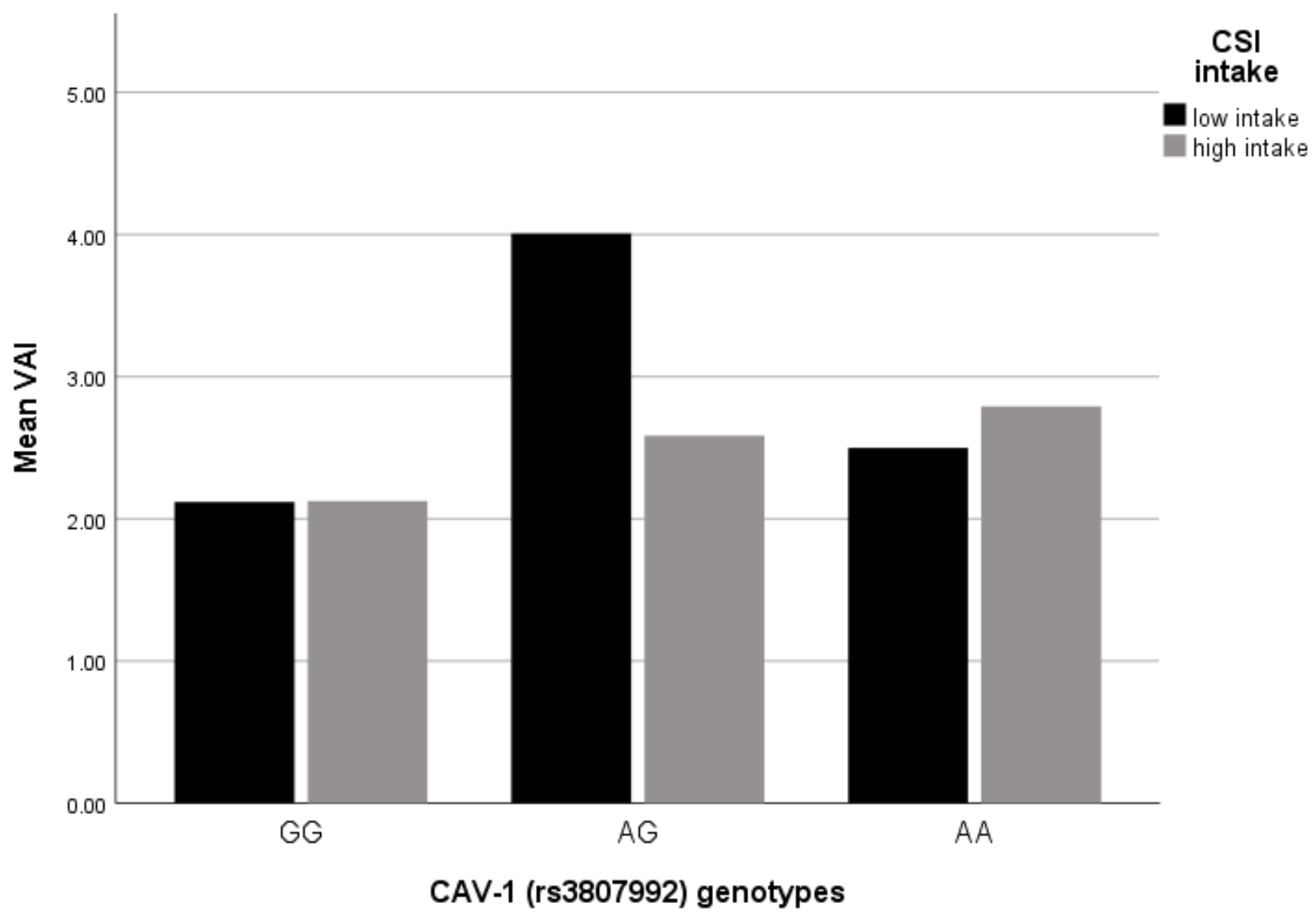

Figure 1

Interaction between CAV-1 genotypes (GG as the reference group) and CSI intake on VAI. VAI (The P-value for AA genotype: 0.61; P-value for CSI intake: 0.99; P-value for interaction between AA genotype and CSI intake: 0.28) 


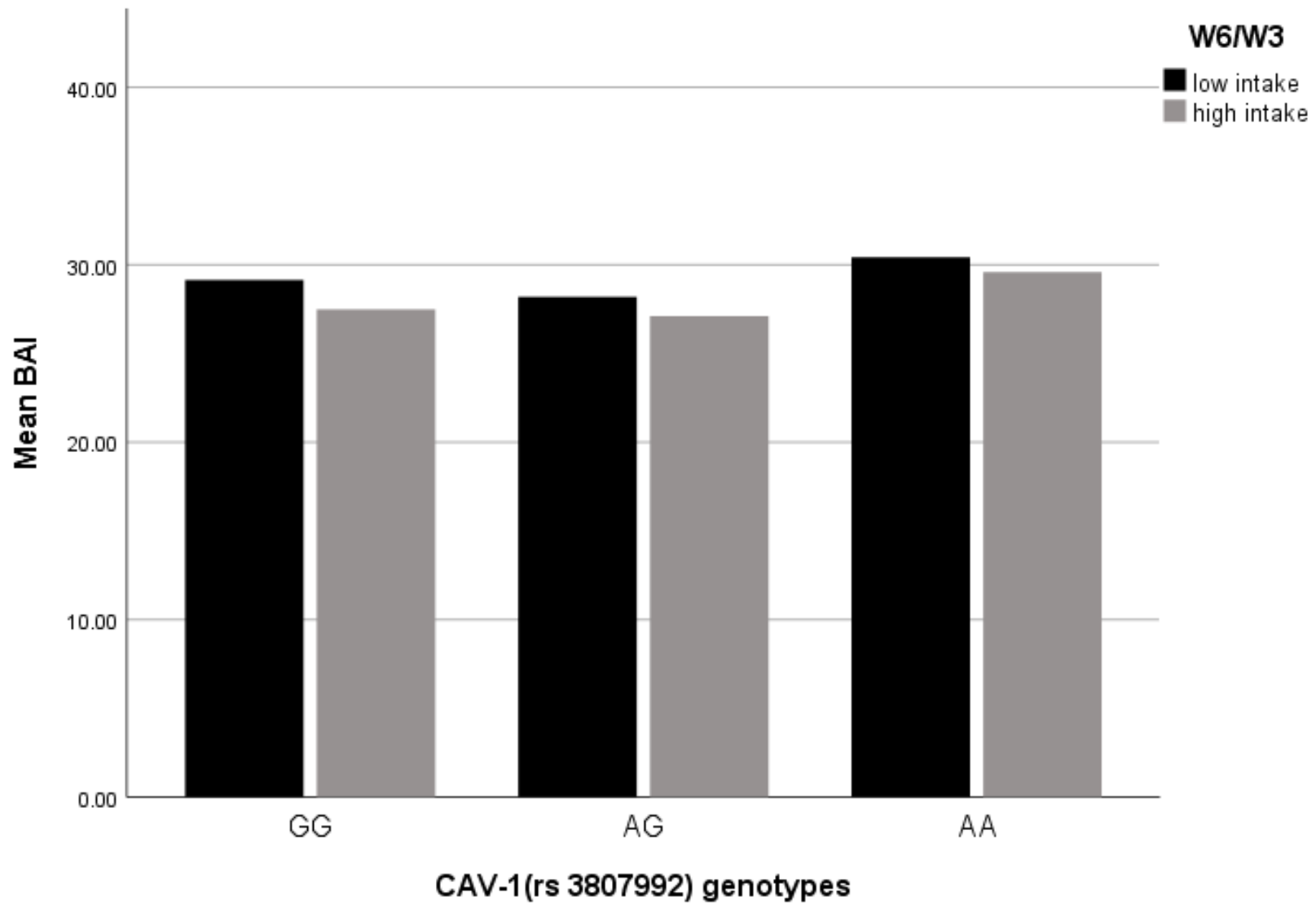

Figure 2

Interaction between CAV-1 genotypes (GG as the reference group) and W6/W3 intake on BAI. VAI (The Pvalue for AA genotype: 0.76; P-value for W6/W3 intake: 0.52; P-value for interaction between AA genotype and W6/W3 intake: 0.76) 


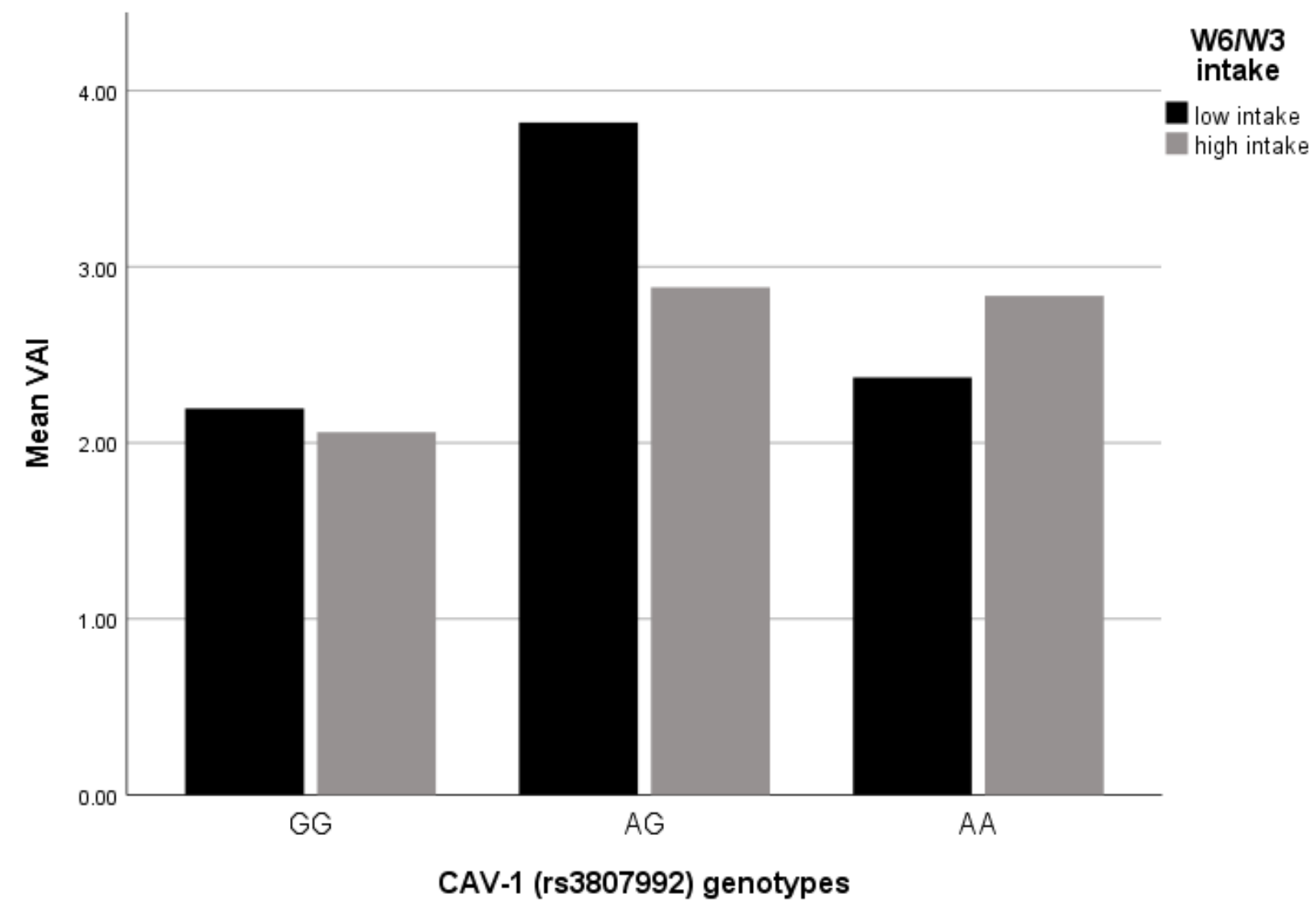

Figure 3

Interaction between CAV-1 genotypes (GG as the reference group) and W6/W3 intake on VAl. VAI (The Pvalue for AA genotype: 0.51; P-value for W6/W3 intake: 0.80; P-value for interaction between AA genotype and W6/W3 intake: 0.50 ) 